\title{
Expression profile and molecular genetic regulation of cyclin D1 expression in epithelioid sarcoma
}

\author{
Lin Lin ${ }^{1}$, David Hicks ${ }^{1}$, Bo Xu ${ }^{1}$, Jessica E Sigel ${ }^{1}$, Wilma F Bergfeld ${ }^{1}$, Elizabeth Montgomery ${ }^{2}$, \\ Cyril Fisher ${ }^{3}$, Marybeth Hartke ${ }^{1}$, Raymond Tubbs ${ }^{1}$ and John R Goldblum ${ }^{1}$ \\ ${ }^{1}$ Cleveland Clinic Foundation, Cleveland, OH, USA; ${ }^{2} J o h n s$ Hopkins Hospital, Baltimore, MD, USA and \\ ${ }^{3}$ Royal Marsden NHS Trust, London, UK
}

\begin{abstract}
Epithelioid sarcoma is a distinctive, aggressive soft tissue tumor typically presenting as a subcutaneous or deep dermal mass in the distal extremities of young adults. Molecular genetic data of well-characterized cases of epithelioid sarcoma are sparse. A recent cytogenetic study of epithelioid sarcoma by conventional metaphase comparative genomic hybridization reported recurrent gains at chromosome 11q13, a region containing many genes, including the cyclin D1 gene. Cyclin D1 is a positive cell cycle regulator that is overexpressed in a variety of neoplasms, including mantle cell lymphoma and breast carcinoma. The objective of this study was to examine cyclin D1 expression in epithelioid sarcoma. Of 24 cases evaluated, 23 (96\%) displayed cyclin D1 nuclear expression using immunohistochemical evaluation. Eight cases, which expressed cyclin D1 by immunohistochemistry, were evaluated by fluorescence in situ hybridization (FISH) and RNA in situ hybridization (RISH) for amplification of the cyclin D1 gene and messenger RNA (mRNA) expression, respectively. Seven of eight cases showed a typical eusomic state. One case showed pseudoamplification due to aneusomy/polysomy. There was no evidence of cyclin D1 gene amplification or messenger RNA overexpression detected by FISH or RNA in situ hybridization analyses, respectively. Our data clearly demonstrate that cyclin D1 protein is upregulated in epithelioid sarcoma, suggesting a role for this cell cycle regulator in the pathogenesis of epithelioid sarcoma. The high level of cyclin D1 protein expression in epithelioid sarcoma appears to be regulated by translational and/or post-translational mechanisms.
\end{abstract}

Modern Pathology (2005) 18, 705-709, advance online publication, 3 December 2004; doi:10.1038/modpathol.3800349

Keywords: cyclin D1 protein expression; epithelioid sarcoma; gene amplification; mRNA expression

Epithelioid sarcoma is a rare, aggressive soft tissue tumor generally presenting as a subcutaneous or deep dermal mass in the upper extremities of adolescents and young adults, and has a high risk for local recurrence and metastasis. ${ }^{1-3}$ Histologically, epithelioid sarcoma is characterized by nodular aggregates of cytologically malignant epithelioid and/or spindled cells, often with central necrosis. The tumor cells are immunoreactive for cytokeratin, epithelial membrane antigen, vimentin, and $50 \%$ of cases are immunoreactive for CD34. ${ }^{4}$

Cytogenetic data for epithelioid sarcoma are relatively sparse. The abnormalities described include $\mathrm{t}(8 ; 22)(\mathrm{q} 22 ; \mathrm{q} 11)$, allelic loss of $22 \mathrm{q}$, gains at

Correspondence: Dr JR Goldblum, MD, Department of Anatomic Pathology, The Cleveland Clinic Foundation, 9500 Euclid Avenue, Cleveland, OH 44195, USA.

E-mail: goldblj@ccf.org

Received 29 July 2004; revised and accepted 26 October 2004; published online 3 December 2004 1q, 6p, and 9q, and aberrations of $18 \mathrm{q}$ and $8 \mathrm{q} \cdot{ }^{2}$ Recent cytogenetic data by conventional metaphase comparative genomic hybridization (CGH) have shown recurrent gains at $11 \mathrm{q} 13,{ }^{5}$ a region with many genes, including the cyclin D1 gene. Cyclin D1, originally identified as a molecule that links growth factor signaling and cell cycle machinery, is a critical molecule in the regulation of progression through the G1 phase of the cell cycle, thereby promoting cell proliferation. ${ }^{6-8}$ The cell cycle progression is tightly regulated by cell cycle regulatory molecules, including cyclins, cyclin-dependent kinases (CDKs) and CDK inhibitors. Cyclin D1 together with CDK are responsible for the G1/S transition by phosphorylating the retinoblastoma $(\mathrm{Rb})$ protein, which then releases transcription factors important for the initiation of DNA replication. ${ }^{9}$ Expression of cyclin D1 gene is upregulated in several neoplasms, including mantle cell lymphoma, ${ }^{10,11}$ multiple myeloma, breast carcinoma, ${ }^{12,13}$ pancreatic endocrine tumors ${ }^{14,15}$ and various sarco- 
mas. ${ }^{16-20}$ However, the role of cyclin D1 in the pathogenesis of epithelioid sarcoma has not been evaluated. In this study, we examine cyclin D1 gene expression in epithelioid sarcoma by immunohistochemistry (IHC), fluorescence in situ hybridization (FISH), and RNA in situ hybridization (RISH).

\section{Materials and methods}

The files of the Departments of Anatomic Pathology of the Cleveland Clinic Foundation, Johns Hopkins Hospital, and Royal Marsden NHS Trust were searched for cases of epithelioid sarcoma. Following review of the hematoxylin and eosin-stained sections, a representative paraffin block from 24 cases of epithelioid sarcoma was selected for immunohistochemical evaluation using an antibody to cyclin D1 (Novocastra, Burlingame, CA, USA) with a modified avidin-biotin complex technique. Appropriate positive and negative controls were used throughout the study. Only nuclear staining was considered positive for cyclin D1. The extent of immunoreactivity was evaluated in a semiquantitative manner using the following scale: $0:<5 \%$ of nuclei staining; $1+: 6-25 \%$ of nuclei staining; $2+$ : $26-50 \%$ of nuclei staining; $3+: 51-75 \%$ of nuclei staining; $4+:>75 \%$ of nuclei staining.

Eight cases of epithelioid sarcoma showing strong cyclin D1 protein expression were selected for FISH and RISH to assess cyclin D1 gene amplification and messenger RNA (mRNA) expression, respectively. FISH was performed on $4 \mu \mathrm{m}$ thick paraffin-embedded sections of tumor tissue, as described previously. ${ }^{21,22}$ After deparaffinization, cell conditioning using Target Retrieval Solution (DakoCytomation, Carpinteria, CA, USA) and proteinase $\mathrm{K}$ treatment, each section was hybridized with $10 \mu \mathrm{l}$ of a dual labeled probe containing a spectrum green label for the centromeric region of chromosome 11 (CEP 11) and a spectrum orange label for the CCND1 locus (Vysis, Downers Grove, IL, USA) and coverslipped. The sections were incubated at $90^{\circ} \mathrm{C}$ for $6 \mathrm{~min}$ and then overnight at $37^{\circ} \mathrm{C}$ in a humidified chamber. Posthybridization washes were performed using $2 \times$ saline sodium citrate (SSC) at room temperature for $5 \mathrm{~min}, 2 \times \mathrm{SSC}$ for $3 \mathrm{~min}$ at $72^{\circ} \mathrm{C}$, and phosphate-buffered saline (PBS)/0.1\% Tween 20 (pH 7.4) for $5 \mathrm{~min}$, and the sections were counterstained with $15 \mu \mathrm{l}$ of DAPI $(0.1 \mu \mathrm{l} / \mathrm{ml})$ in antifade solution (Ventana Medical Systems, Tucson, AZ, USA). Signals were visualized using an Olympus BX40 fluorescence microscope (Olympus America, Melville, NY, USA) with three band pass filters. Amplification of epidermal growth factor receptor $(E G F R)$ gene on chromosome $7 \mathrm{p} 12$ in a case of glioblastoma was used as a positive control for gene amplification. Signals from 20 nuclei in two representative fields were evaluated, and the mean of each field calculated. The means of the two field counts were recorded as the result for two cases.
Amplification was defined as a CCDN1/CEP11 ratio $\geq 2.0$, and polysomy was defined as a CEP11 average count > 3.0; only nuclei with at least one CEP11 signal were counted.

The $3^{\prime}$-UTR region $(\sim 0.4 \mathrm{~kb})$ of cyclin D1 gene was amplified by RT-PCR using total RNA from human the monocytic cell line, U937 (ATCC). The cDNA fragments were then subcloned into a pCMV vector bearing both T3 and T7 promoters (Stratagene, La Jolla, CA, USA). The sense and antisense cRNA probes were labeled with digoxigenin-UTP (DIG-UTP) by in vitro transcription with either T3 or T7 RNA polymerase (Roche, Indianapolis, IN, USA) using pCMV-cyclin D1-3'-UTR as templates. The digoxigenin-labeled GAPDH probe was a kind gift from Ventana Medical Systems. The in situ hybridization reactions on formalin-fixed, paraffin-embedded tissue sections were carried out on a Discovery automated system (Ventana) following the manufacturer's protocol.

\section{Results}

All 24 cases of epithelioid sarcoma evaluated in this study displayed typical histologic features, including nodular collections of cytologically malignant epithelioid and spindled cells with eosinophilic cytoplasm separated by dense collagen and often revealing central necrosis (Figures 1 and 2). Immunohistochemically, 23 of 24 (96\%) cases showed some degree of cyclin D1 nuclear expression (Table 1). In one-half of the cases, at least $50 \%$ of the neoplastic nuclei stained positively for cyclin D1 (Figure 3), including 10 cases with $3+$ staining and two cases with $4+$ staining.

Eight cyclin D1-immunoreactive cases were further evaluated by FISH. Seven of the eight cases showed a typical diploid state. One case displayed

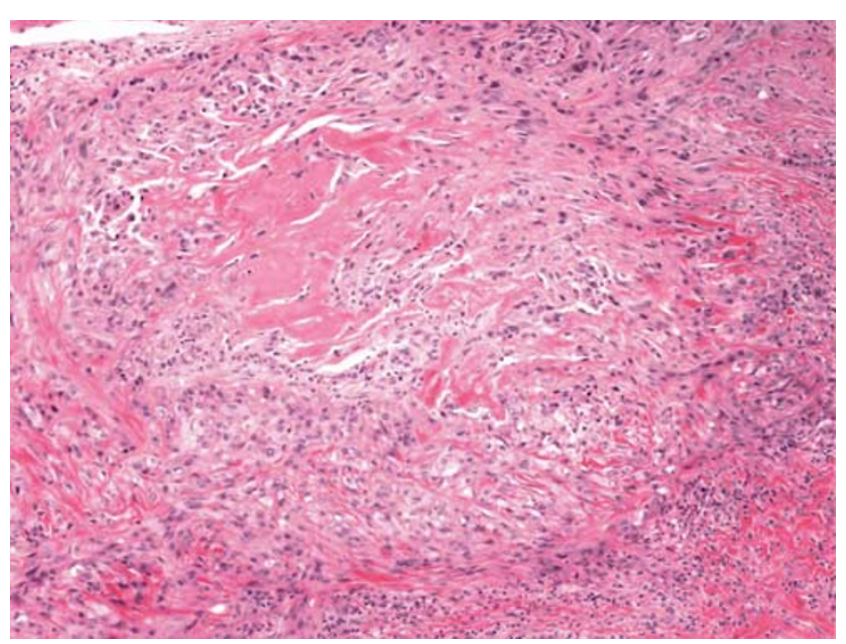

Figure 1 Typical example of cutaneous epithelioid sarcoma. The tumor is composed of a sheet-like proliferation of large epithelioid cells and spindled cells with central necrosis in a garland pattern. 


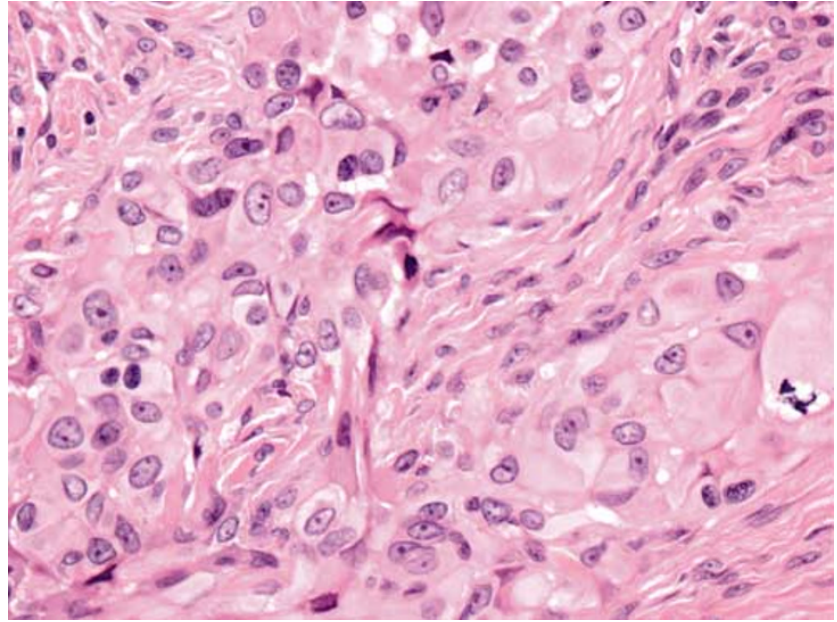

Figure 2 High-magnification view of epithelioid sarcoma composed of large epithelioid cells with atypical nuclei and abundant eosinophilic cytoplasm.

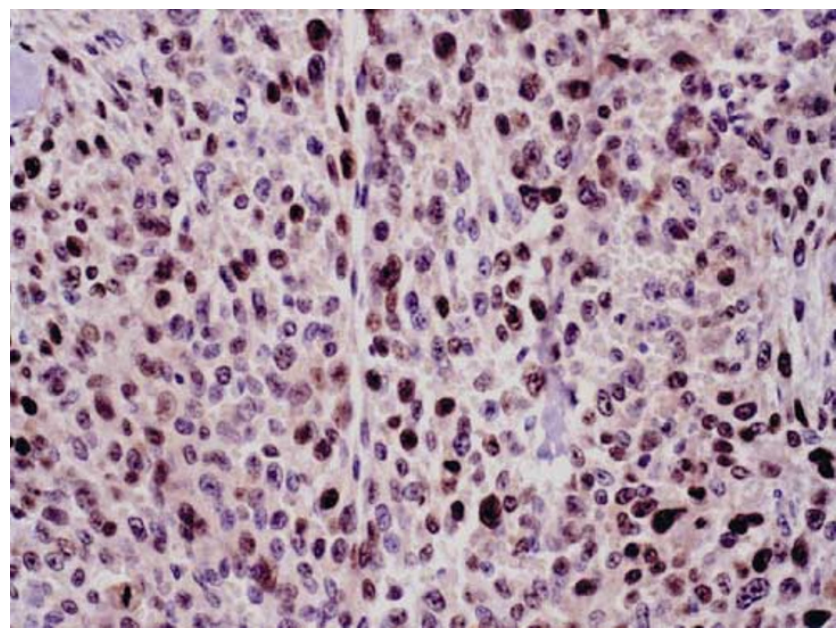

Figure 3 High-magnification view of cyclin D1 immunoreactivity in a case of epithelioid sarcoma. Note the strong and diffuse nuclear staining for this antigen.

Table 1 Cyclin D1 immunoreactivity in epithelioid sarcoma

\begin{tabular}{lc}
\hline Immunostaining & Epithelioid sarcoma \\
\hline Negative (0) & $1 / 24(4 \%)$ \\
Positive & $23 / 24(96 \%)$ \\
$1+$ & $6 / 24$ \\
$2+$ & $5 / 24$ \\
$3+$ & $10 / 24$ \\
$4+$ & $2 / 24$ \\
\hline
\end{tabular}

pseudoamplification due to aneusomy/polysomy. While cyclin D1 protein was upregulated in almost all cases of epithelioid sarcoma (96\%), there was no evidence of cyclin D1 gene amplification (Figure 4) as evidenced by FISH analysis. To further investi-
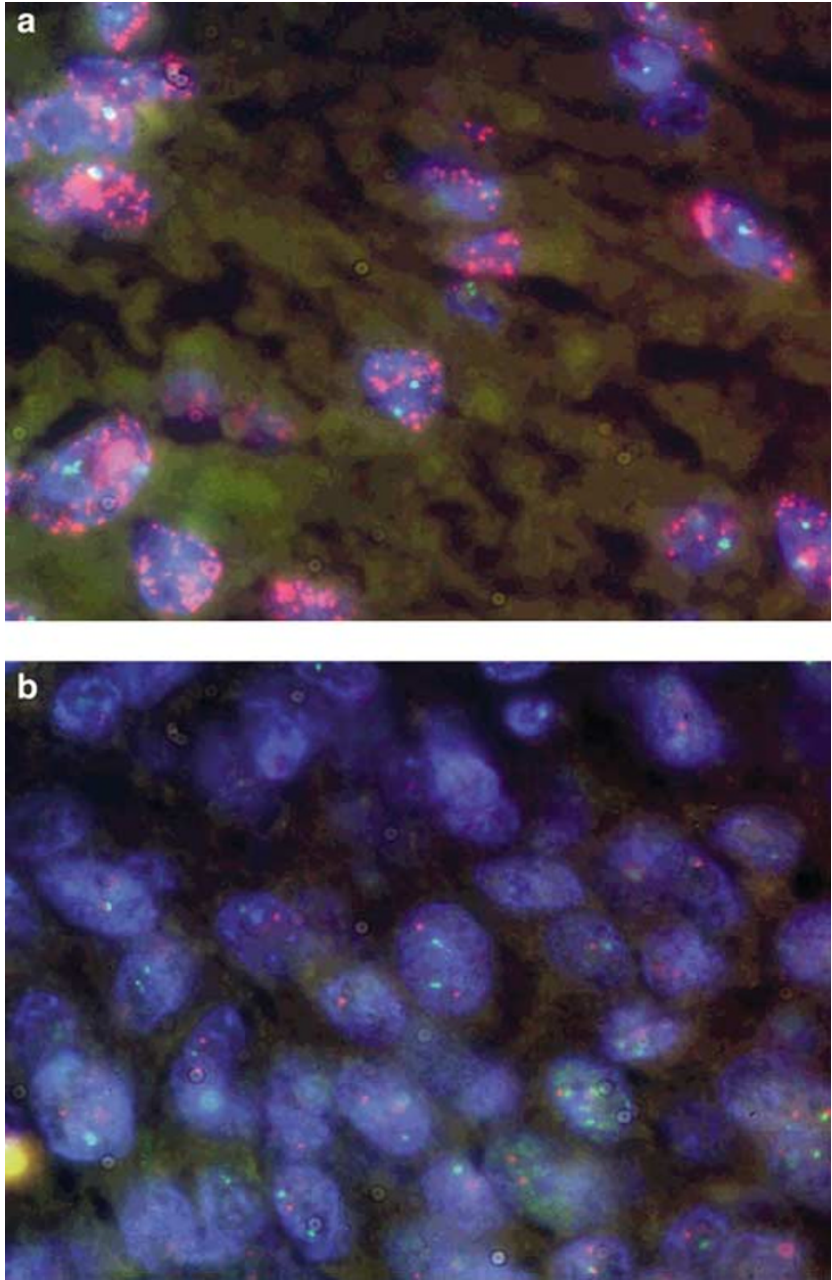

Figure 4 FISH analysis of cyclin D1 gene status in epithelioid sarcoma. Multiple red dots, representing multiple copies of EGFR gene, in each nucleus (a), indicate EGFR gene amplification in a case of glioblastoma multiforme (GBM), which served as a positive control for gene amplification. However, only two red dots, representing two copies of cyclin D1 gene, are observed in each nucleus of epithelioid sarcoma, indicating an absence of cyclin D1 gene amplification in epithelioid sarcoma (b).

gate the mechanism underlying the high-level expression of cyclin D1 protein in epithelioid sarcoma, cyclin D1 mRNA expression level was examined by RISH. Although strong staining for cyclin D1 mRNA was found in highly proliferating epidermis, there was no staining for cyclin D1 in neoplastic cells (Figure 5b). In contrast, positive staining for GAPDH mRNA was found in all sections examined, including the tumor cells (Figure 5a), serving as a positive control for preservation of mRNA, and therefore indicates that these sections are suitable for RISH.

\section{Discussion}

Cyclin D1 participates in cell cycle progression through G1 phase and transition from G1 to S phase. The cyclin D1 gene, CCND1, is located on chromo- 
708
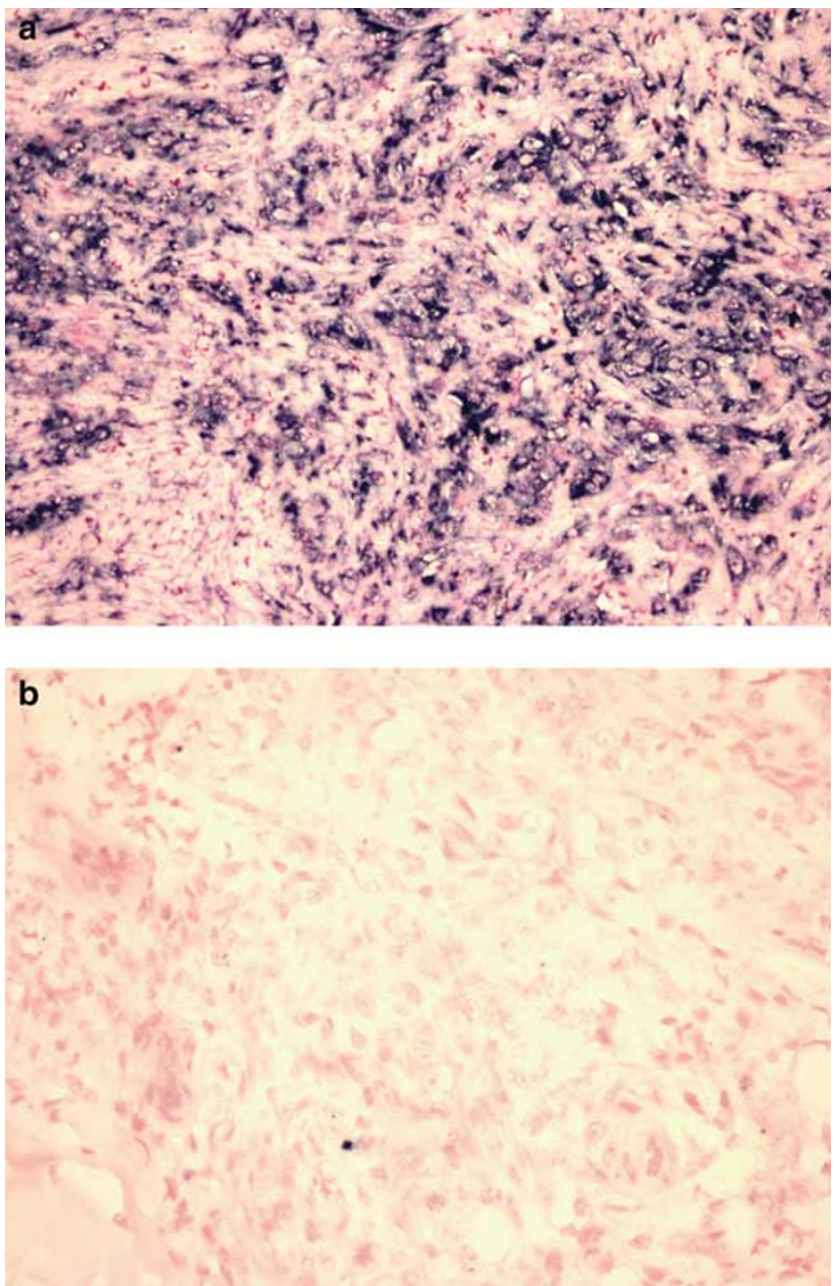

Figure 5 RISH analysis of cyclin D1 mRNA expression in epithelioid sarcoma. The positive GAPDH mRNA staining is seen in epithelioid sarcoma throughout the section (a). Whereas cyclin D1 mRNA is not found in the tumor cells (b).

some $11 \mathrm{q} 13$ and is amplified in a wide range of human tumors. Amplification and/or overexpression of cyclin D1 have been suggested to play a crucial role in tumorigenesis in a diverse group of neoplasms, including mantle cell lymphoma, carcinomas of the breast, lung, colorectum, multiple myeloma, and pancreatic endocrine tumors. ${ }^{10-14,16,23}$ Although it has been speculated that cyclin D1 may also be altered in epithelioid sarcoma, ${ }^{5}$ data on cyclin D1 expression in epithelioid sarcoma are limited. We found nuclear cyclin D1 protein expression in $96 \%$ of epithelioid sarcoma cases examined. In one-half of the cases, at least $50 \%$ of the cells showed nuclear expression of cyclin D1, suggesting a role of cyclin D1 in the pathogenesis of this tumor.

The expression of cyclin D1 gene is a complex process and can be regulated at multiple levels. Amplification/translocation of CCND1 locus can result in increased expression of both mRNA and protein levels of cyclin D1. Indeed, in mantle cell lymphoma and other B-cell chronic lymphoproliferative disorders and in subsets of multiple myeloma, the chromosomal translocation $\mathrm{t}(11 ; 14)(\mathrm{q} 13 ; 32)$ results in rearrangement of CCND1 and overexpression of cyclin D1 protein. ${ }^{10,11,24}$ However, expression of cyclin D1 protein is not always associated with CCND1 locus rearrangements, since high frequencies of cyclin D1 overexpression accompanied by low incidences of $C C N D 1$ amplification have been reported in several neoplasms including melanomas, sarcomas, colorectal and uterine cancers. ${ }^{19,25}$ It has been suggested that increased transcriptional activity of cyclin D1 gene may be regulated by intracellular signaling events leading to activation of various transcription factors. In fact, several kinase pathways, such as mitogen-activated protein kinases (p38 and p42/44 MAPK) and c-Jun amino terminal (N-terminal) kinase transmit exogenous growth signals to upregulate cyclin $\mathrm{D} 1 .^{26,27}$ Similarly, activation of the protein kinase B pathway can also increase cyclin D1 expression through either transcriptional or post-transcriptional mechanisms. ${ }^{28-30}$

In this study, we found there was no evidence of amplification of the cyclin D1 gene or elevation of cyclin D1 mRNA in cases of epithelioid sarcoma that showed strong nuclear cyclin D1 expression. Thus, overexpression of cyclin D1 protein in epithelioid sarcoma likely occurs at translational and/or posttranslational levels. It has been reported in an in vitro study that cyclin $\mathrm{D} 1$ protein induction in the G2 phase of the cell cycle does not require de novo mRNA synthesis, ${ }^{31}$ indicating that cyclin D1 protein induction is mainly mediated by a translational or post-translational mechanism. It has been suggested that mTOR/PI3 kinase regulated p70S6 kinase-dependent control and/or PI3 kinase/eIF4Emediated control may participate in cyclin D1 translational control. ${ }^{32-36}$ In addition, a study from human sarcoma cell lines has suggested that overexpression of cyclin D1 protein may result from enhanced protein stability due to an altered ubiquitin/proteasome pathway involved in the degradation of cyclin D1 protein. ${ }^{37}$ Therefore, it is possible that translational/post-translational regulation of cyclin D1 protein may provide a timing fashion for control of rapid cell cycle progression. The precise mechanism for cyclin D1 protein upregulation in epithelioid sarcoma remains to be elucidated.

In summary, we report very frequent (96\%) nuclear expression of cyclin D1 protein in epithelioid sarcoma. Since there was no genetic abnormality detected in the cyclin D1 locus (CCDN1) nor elevation of cyclin D1 mRNA levels, the expression of cyclin D1 protein in epithelioid sarcoma is apparently regulated by translational and/or posttranslational mechanisms. To our knowledge, this is the first study to evaluate genetic alterations in epithelioid sarcoma using FISH and RISH. Using bacterial artificial chromosome (BAC) and array-based CGH may help to determine the genes amplified in the $11 \mathrm{q} 13$ region in epithelioid sarcoma. 


\section{References}

1 Enzinger FM. Epithelioid sarcoma. A sarcoma simulating a granuloma or a carcinoma. Cancer 1970;26: 1029-1041.

2 Weiss SW, Goldblum JR, In: Soft Tissue Tumors. Mosby, Inc.: Marc Strauss, St Louis, 2001, 1532pp.

3 Chase DR, Enzinger FM. Epithelioid sarcoma. Diagnosis, prognostic indicators, and treatment. Am J Surg Pathol 1985;9:241-263.

4 Miettinen M, Fanburg-Smith JC, et al. Epithelioid sarcoma: an immunohistologic analysis of 112 classical and variant cases and a discussion of the differential diagnosis. Hum Pathol 1999;30:934-942.

5 Lushnikova T, Knuutila S, Miettinen M. DNA copy number changes in epithelioid sarcoma and its variants: a comparative genomic hybridization study. Mod Pathol 2000;13:1092-1096.

6 Matsushime $\mathrm{H}$, Roussel MF, Ashmun RA, et al. Colony-stimulating factor 1 regulates novel cyclins during the G1 phase of the cell cycle. Cell 1991; 65:701-713.

7 Matsushime H, Quelle DE, Shurtleff SA, et al. D-type cyclin-dependent kinase activity in mammalian cells. Mol Cell Biol 1994;14:2066-2076.

8 Baldin V, Lukas J, Marcote MJ, et al. Cyclin D1 is a nuclear protein required for cell cycle progression in G1. Genes Dev 1993;7:812-821.

9 Sherr CJ. G1 phase progression: cycling on cue. Cell 1994;79:551-555.

10 Weisenburger DD, Armitage JO. Mantle cell lymphoma-an entity comes of age. Blood 1996;87:4483-4494.

11 Campo E, Raffeld M, Jaffe ES. Mantle-cell lymphoma. Semin Hematol 1999;36:115-127.

12 Cordon-Cardo C. Mutations of cell cycle regulators. Biological and clinical implications for human neoplasia. Am J Pathol 1995;147:545-560.

13 Jares P, Rey MJ, Fernandez PL, et al. Cyclin D1 and retinoblastoma gene expression in human breast carcinoma: correlation with tumour proliferation and oestrogen receptor status. J Pathol 1997;182:160-166.

14 Guo SS, Wu X, Shimoide AT, et al. Frequent overexpression of cyclin D1 in sporadic pancreatic endocrine tumours. J Endocrinol 2003;179:73-79.

15 Chung DC, Brown SB, Graeme-Cook F, et al. Overexpression of cyclin D1 occurs frequently in human pancreatic endocrine tumors. J Clin Endocrinol Metab 2000;85:4373-4378.

$16 \mathrm{Kim}$ SH, Lewis JJ, Brennan MF, et al. Overexpression of cyclin D1 is associated with poor prognosis in extremity soft-tissue sarcomas. Clin Cancer Res 1998;4: 2377-2382.

17 Kim SH, Cho NH, Tallinl G, et al. Prognostic role of cyclin D1 in retroperitoneal sarcomas. Cancer 2001;91: 428-434.

18 Kennedy MM, Biddolph S, Lucas SB, et al. Cyclin D1 expression and HHV8 in Kaposi sarcoma. J Clin Pathol 1999;52:569-573.

19 Maelandsmo GM, Berner JM, Florenes VA, et al. Homozygous deletion frequency and expression levels of the CDKN2 gene in human sarcomas-relationship to amplification and mRNA levels of CDK4 and CCND1. Br J Cancer 1995;72:393-398.

20 Antonescu CR, Leung DH, Dudas M, et al. Alterations of cell cycle regulators in localized synovial sarcoma: a multifactorial study with prognostic implications. Am J Pathol 2000;156:977-983.
21 Frater JL, Tsiftsakis EK, Hsi ED, et al. Use of novel $\mathrm{t}(11 ; 14)$ and $\mathrm{t}(14 ; 18)$ dual-fusion fluorescence in situ hybridization probes in the differential diagnosis of lymphomas of small lymphocytes. Diagn Mol Pathol 2001;10:214-222.

22 Vaziri SA, Tubbs RR, Darlington G, et al. Absence of CCND1 gene amplification in breast tumours of BRCA1 mutation carriers. Mol Pathol 2001;54:259-263.

23 Hall M, Peters G. Genetic alterations of cyclins, cyclindependent kinases, and Cdk inhibitors in human cancer. Adv Cancer Res 1996;68:67-108.

24 Sola B, Salaun V, Ballet JJ, et al. Transcriptional and post-transcriptional mechanisms induce cyclin-D1 over-expression in B-chronic lymphoproliferative disorders. Int J Cancer 1999;83:230-234.

25 Bartkova J, Lukas J, Strauss M, et al. Cyclin D1 oncoprotein aberrantly accumulates in malignancies of diverse histogenesis. Oncogene 1995;10:775-778.

26 Lavoie JN, L'Allemain G, Brunet A, et al. Cyclin D1 expression is regulated positively by the $\mathrm{p} 42$ / p44MAPK and negatively by the p38/HOGMAPK pathway. J Biol Chem 1996;271:20608-20616.

27 Lee RJ, Albanese C, Stenger RJ, et al. pp60(v-src) induction of cyclin D1 requires collaborative interactions between the extracellular signal-regulated kinase, p38, and Jun kinase pathways. A role for cAMP response element-binding protein and activating transcription factor-2 in pp60(v-src) signaling in breast cancer cells. J Biol Chem 1999;274:7341-7350.

28 Gille H, Downward J. Multiple ras effector pathways contribute to G(1) cell cycle progression. J Biol Chem 1999;274:22033-22040.

29 Diehl JA, Cheng M, Roussel MF, et al. Glycogen synthase kinase-3beta regulates cyclin D1 proteolysis and subcellular localization. Genes Dev 1998;12: 3499-3511.

30 Muise-Helmericks RC, Grimes HL, Bellacosa A, et al. Cyclin D expression is controlled post-transcriptionally via a phosphatidylinositol 3-kinase/Akt-dependent pathway. J Biol Chem 1998;273:2986429872.

31 Guo Y, Stacey DW, Hitomi M. Post-transcriptional regulation of cyclin D1 expression during G2 phase. Oncogene 2002;21:7545-7556.

32 Choi YH, Lee SJ, Nguyen P, et al. Regulation of cyclin D1 by calpain protease. J Biol Chem 1997;272: 28479-28484.

33 Hashemolhosseini S, Nagamine Y, Morley SJ, et al. Rapamycin inhibition of the $\mathrm{G} 1$ to $\mathrm{S}$ transition is mediated by effects on cyclin D1 mRNA and protein stability. J Biol Chem 1998;273:14424-14429.

34 Langenfeld J, Kiyokawa H, Sekula D, et al. Posttranslational regulation of cyclin D1 by retinoic acid: a chemoprevention mechanism. Proc Natl Acad Sci USA 1997;94:12070-12074.

35 Jefferies HB, Fumagalli S, Dennis $\mathrm{PB}$, et al. Rapamycin suppresses 5'TOP mRNA translation through inhibition of p70s6k. EMBO J 1997;16:36933704.

36 Rosenwald IB, Lazaris-Karatzas A, Sonenberg N, et al. Elevated levels of cyclin D1 protein in response to increased expression of eukaryotic initiation factor $4 \mathrm{E}$. Mol Cell Biol 1993;13:7358-7363.

37 Welcker M, Lukas J, Strauss M, et al. Enhanced protein stability: a novel mechanism of D-type cyclin overabundance identified in human sarcoma cells. Oncogene 1996;13:419-425. 